\title{
A tradição francesa de crítica sociológica à Economia Política
}

\author{
Philippe Steiner*
}

\section{Resumo}

O texto defende a tese segundo a qual existe uma tradição que vai de Comte a Bourdieu passando por Durkheim e durkheimianos e que esta tradição é de natureza intelectual. O texto parte de uma apresentação das três principais formas de crítica sociológica da Economia Política que existem desde o final do século XIX. A seguir mostra que a posição defendida pelos três sociólogos franceses não pode ser explicada somente por sua formação ou por sua relação (distanciada) com a Economia Política e ressalta a filiação intelectual dos três, que visa desqualificar cientificamente a Economia Política em razão do papel dado às representações sociais, sejam as engendradas pela atividade econômica ela mesma, sejam aquelas construídas previamente através das instituições escolares.

Palavras-chave: Sociologia Econômica, crítica da Economia Política, representações sociais.

\section{Introdução}

\begin{abstract}
A s obras de Augusto Comte, Émile Durkheim e Pierre Bourdieu Aoferecem uma continuidade surpreendente para o leitor interessado na sua relação com a Economia Política. De fato, os três grandes sociólogos criticam essa ciência social em razão dos erros metodológicos cometidos pelos economistas. Tal desqualificação da Economia Política conduz todos os três a conferir à Sociologia do Conhecimento
\end{abstract}

Professor da Universidade de Paris IV (Sorbonne). Endereço eletrônico: Philippe.

Steiner@paris-sorbonne.fr. 
um papel central tanto na crítica como quando se trata de definir os desafios práticos que a sua crítica coloca em primeiro plano. ${ }^{1}$

Defenderemos a tese segundo a qual existe uma tradição intelectual que vai de Comte a Bourdieu, passando por Durkheim e os durkheimianos (ver anexo 1 para informações historiográficas). Ressaltemos de início que o presente texto não pretende defender a idéia da existência de uma tradição francesa de crítica da Economia Política, no sentido de que ela seria tipicamente francesa. É fácil demonstrar que tal idéia é errônea. De um lado, existem fortes críticas da Economia Política que, por não saírem da pena de um sociólogo (no sentido da posição acadêmica), não se encontram menos próximas da crítica sociológica que existe na obra de Émile Durkheim e François Simiand, como é o caso de Thorstein Veblein (GISLAIN \& STEINER, 1999). Por outro lado, existem sociólogos e filósofos franceses que, embora abordem de maneira detalhada os problemas teóricos e históricos apresentados pela Economia Política, apreendem esse fato social de um modo crítico muito distinto, como se pode observar com Raymond Boudon (1995; 1998; 2002) ou com Michel Focault (1978; 1979). Além disso, à exceção de Comte, essa crítica é alimentada com referências a trabalhos estrangeiros (ver anexo 2).

Para evidenciar a originalidade da tradição intelectual examinada aqui, nós a compararemos de início às críticas formuladas por Karl Marx de um lado e por Vilfredo Pareto e Max Weber de outro. Essa comparação é necessária por duas razões: primeiramente ela permite comparar a "reforma" da Economia Política de Comte com a crítica da Economia Política assumida por Marx n'O capital, haja vista que ela permite situar as críticas de Durkheim e Bourdieu vis-à-vis aquelas dos dois grandes sociólogos economistas clássicos (seção 1). Veremos em seguida que a posição dos três sociólogos

1 Artigo publicado na Revue d'Histoire des Sciences Humaines (Paris, v. 17, maio de 2008, p. 63-84); uma primeira versão foi apresentada no Colóquio “Traditions Nationales en Sciences Sociales", realizado em maio de 2005 na Amsterdam School for Social Science Research. Agradecemos as gentis permissões dos editores e do autor para a tradução. Tradução de Marcia da Silva Mazon e Luis Hernan A. P. Mendoza e revisão da tradução de Gustavo Biscaia de Lacerda e Cécile Raud. 
franceses não pode ser explicada somente pela formação deles ou por sua relação (distanciada) com a Economia Política (seção 2). Ressaltaremos, então, sua filiação intelectual que visa a desqualificar cientificamente a Economia Política em razão do papel conferido às representações sociais, quer sejam elas engendradas pela própria atividade econômica, quer sejam provenientes da sua construção social por intermédio da instituição escolar (seção 3).

\section{A economia como 'falsa ciência': de Comte a Bourdieu passando por Durkheim}

A crítica da Economia Política não é uma preocupação exclusiva dos sociólogos. Os economistas foram os primeiros críticos do seu próprio saber: no século XVIII, desde que o projeto de uma ciência econômica foi formulado pelos Fisiocratas; posteriormente, no século XIX, quando dos debates sobre o método mantidos entre os economistas clássicos (STEINER, 1998, cap. 2 e 4). É necessário então começar por esclarecer a natureza da crítica sociológica da Economia Política antes de buscar caracterizar a posição dos sociólogos franceses.

Quando se trata da crítica sociológica da Economia Política, é preciso distinguir entre três opções que aparecem nas viradas dos séculos XIX e XX (STEINER, 1999: 10-12). A posição de Comte, Durkheim e Bourdieu têm por alternativas a posição de Pareto, por um lado, e a de Weber e Joseph Schumpeter, por outro.

A crítica de Pareto se insere dentro de uma estratégia de complemento. Partindo da Economia Política pura, Pareto sugere tornar mais complexo o modelo teórico com o qual se busca compreender a atividade econômica e social, acrescentando a economia aplicada e em seguida a Sociologia. Segundo Pareto, o homo economicus da teoria pura não passa de uma primeira aproximação, tornada mais complexa quando se considera que esse homo economicus tem paixões outras que não as econômicas, de modo a resultar no ser social ainda mais complexo, composto de homo economicus, homo religiosus, homo sexualis etc., do qual trata a Sociologia. Portanto, a Economia Política pura não está condenada pela sua abstração. Antes, a estratégia paretiana consiste na afirmação repetida e ar- 
gumentada segundo a qual a economia pura e a economia aplicada não bastam para a explicação dos fatos concretos.

Weber e Schumpeter seguem uma estratégia de adaptação, visando a produzir o encontro da Economia Política e da Sociologia, para relacionar a teoria (econômica) e a singularidade (histórica) por meio de tipos ideais elaborados pela Sociologia Econômica. Tratase, então, de definir as ferramentas intermediárias graças às quais os conceitos da teoria econômica podem explicar configurações históricas particulares, eventualmente únicas. A Economia Política (o marginalismo da escola austríaca, neste caso) não é rejeitada pela sua abstração; entretanto, ela é qualificada sociologicamente de modo a permitir uma explicação da vida econômica e social.

Portanto, essas duas estratégias críticas têm algo de particular, a saber, os autores que as formulam não buscam nunca desqualificar a teoria econômica, tal qual ela existe. Isso permanece verdadeiro, mesmo quando a crítica ao economicismo - isto é a postura equivalente a considerar apenas a teoria econômica para explicar um fato histórico concreto - adquira uma forma contundente, tal como ocorre ocasionalmente em Pareto. Aliás, Pareto e Shumpeter são, com justiça, considerados teóricos de primeira ordem na esfera da economia política. As suas respectivas estratégias visam, antes e sobretudo, a melhorar o "rendimento científico" da teoria econômica, caso possamos assim nos expressar, durante um período no qual esta última era alvo de numerosas críticas, em sua maioria oriundas dos próprios economistas.

Os três sociólogos franceses adotam uma estratégia de substituição da Economia Política pela Sociologia ${ }^{2}$. Para eles, a Economia

2 Comte fala frequientemente da Economia Política como de uma "pretensa ciência" (COMTE, 1830-42, II, p. 92, 94, 95 etc.), "apesar da afetação ilusória das formas especiais e do protocolo habitual da linguagem científica” (ibid., p.93). Adiante, ele afirma: "O que se vê, em resumo, é que a apreciação política dessa pretensa ciência confirma essencialmente o que provavelmente tornaria possível prever a sua apreciação científica direta, testemunhando que não se deve, em hipótese alguma, nela entrever um elemento constituído da futura Física Social”. Esta última, sob o nome de Sociologia, é esboçada na lição 49 do Curso. Para Durkheim, a característica defeituosa da Economia Política consiste em representar um saber no qual a ideologia - o estudo das idéias que os cientistas elaboram acerca de um problema (uma abstração), muito 
Política é uma pseudociência da qual a Sociologia - ela sim uma verdadeira ciência - deve livrar-se, quer seja substituindo esse falso saber por uma teoria sociológica geral (Comte e Bourdieu), quer seja substituindo-a por uma Sociologia especial, a Sociologia Econômica (Durkheim e os durkheimianos). Os três sociólogos franceses atribuem à sua estratégia de substituição uma notável continuidade temporal, contrariamente a Pareto e Weber, cujas posições críticas estão localizadas no tempo e no espaço das teorias ${ }^{3}$. Formulada nos anos 1830 por Comte, retomada nos anos 1890-1900 por Durkheim, desenvolvida nas décadas 1910-1930 por Simiand, ela ressurge nos anos 1995-2000, na última parte da obra de Bourdieu. Ora, a teoria econômica conheceu muitas transformações entre esses três períodos e aquela à qual os três autores dirigem-se difere sensivelmente: a economia clássica de Adam Smith e Jean-Baptiste Say, no tocante a Comte, a economia liberal francesa e a escola histórica alemã, no que se refere a Durkheim, e a economia dita mainstream, para Bourdieu ${ }^{4}$. A consequiência é simples: os sociólogos franceses

mais que o estudo do problema em si - produz estragos (DURKHEIM, 1894, p. 23-24). Embora as expressões públicas de Durkheim sejam prudentes, a correspondência com Celestin Bouglé mostra que Durkheim considera o estudo do fato social econômico como algo totalmente por fazer: "Dela [da Economia Política], eu nada extraí salvo o que pode ensinar uma experiência negativa. É verdade que, em razão disso, há nessa área um campo virgem para explorações. Com a estatística e a história, provavelmente, far-se-ia grandes descobertas" (carta de 16.5.1896, in: DURKHEIM, 1975, II, p.392). Na última fase dos seus trabalhos, Bourdieu busca, também ele, "uma teoria alternativa para compreender a ação econômica" graças ao conceito de habitus (BOURDIEU, 2000, p.11). Com esse conceito é possível tentar "reconstruir, por um lado, a gênese das disposições econômicas do agente econômico e, especialmente, seus gostos, suas necessidades, suas propensões ou hábitos, assim como, por outro lado, a gênese do próprio campo econômico, ou seja, elaborar a história do processo de diferenciação e autonomização que resultou na constituição desse jogo específico: o campo econômico como cosmos obedecendo às suas próprias leis" (ibid., p.16) - e isso no lugar da "matematização do senso comum" a que se dedicam os economistas (ibid., p.13).

3 A Economia Política liberal francesa e a economia matemática de Leon Walras, para Pareto, e a escola histórica e o marginalismo da escola austríaca, para Weber, são as teorias frente às quais eles reagem em particular.

4 A economia liberal francesa foi bem definida por Lucette Levan-Lemesle (2004), que a caracteriza por meio do grupo formado em torno de uma revista (o Journal des économistes), de uma sociedade (a Société d'Économie politique) e de um editor (Guillaumin). Os dois primeiros pilares estão ainda muito presentes na 
criticam não tal ou qual forma da teoria econômica, mas a teoria econômica, enquanto uma maneira de fazer ciência social. Pode-se mesmo sustentar a idéia segundo a qual a sua Sociologia consiste em um contradiscurso político face ao discurso político representado pela Economia Política ${ }^{5}$, caso consideremos o fato de a Economia Política ser uma forma de governo fundado na idéia basilar do comportamento racional interessado das populações (FOUCAULT, 1977; 1978).

\section{A crítica sociológica e sua relação com a Economia Política}

A estratégia adotada pelos três sociólogos franceses explicarse-ia por meio da natureza da sua relação com a Economia Política? Com efeito, essa estratégia advém de sociólogos, ao passo que as outras estratégias vêm de economistas (Pareto, Schumpeter e Weber). Em outros termos, cabe questionar se a formação intelectual dá conta da estratégia dos sociólogos franceses. De maneira mais direta, a crítica virulenta não seria fruto da ignorância (relativa) destes últimos?

No que diz respeito à formação intelectual, a Filosofia impera, pois Durkheim e Bourdieu foram alunos da École Normale Supérieure, mestre em Filosofia. Certa e igualmente, Comte é caracterizado por uma forte orientação filosófica, porém a sua formação inicial é aquela própria a um cientista, em virtude da sua excelente acolhida na École Polytechnique (anteriormente à sua exclusão, por motivos políticos, por ter se recusado a dobrar-se às condições exigidas para a sua reintegração) e em razão de ele sobreviver como professor particular de matemática nesse estabelecimento.

A formação dos autores acima contrasta com aquelas de Pareto, Schumpeter e Weber. Pareto tem uma formação como engenheiro e uma atividade como dirigente empresarial, antes de voltar-se para

época de Durkheim. A economia dita mainstream, à qual se dirige Bourdieu, é de mais difícil caracterização, porém é possível fazê-lo insistindo sobre o uso feito dos conceitos de "ator racional”, "equilíbrio" e "otimização".

5 A esse respeito, permito-me indicar um artigo recente no qual avancei essa idéia a propósito da crítica comtiana (STEINER, 2006); a idéia segundo a qual a Economia Política seria um discurso político foi posteriormente elaborada em termos da história das Ciências Sociais (FACCARELLO \& STEINER, 2007). 
o ensino, em razão do insucesso de uma carreira política. Schumpeter tem uma formação jurídica e econômica, adquirida na Áustria, na Alemanha e na Inglaterra, e a sua "vocação" como economista aparenta ter sido precoce (SWEDBERG, 1991, cap. 1). Quanto a Weber, a sua riquíssima formação inicial engloba o Direito, a Teologia e a Economia; em seguida, ele orientou-se para a Economia Política, tal qual estabelecida pelo Verein für Sozialpolitik de Gustav Schmoller, porém com a independência intelectual que lhe é própria.

Essas diferenças são importantes. Entretanto, seriam elas suficientes para a explicação das estratégias adotadas? É possível duvidar. No fim das contas, a formação científica de Pareto compartilha vários pontos em comum com aquela de Comte; igualmente, $\mathrm{o}$ interesse de Schumpeter e de Weber pela Filosofia é tão conhecido quanto a importância atribuída por Durkheim ao Direito em seus primeiros trabalhos, muito particularmente na sua tese de Filosofia: Da divisão do trabalho social. Além disto, a formação filosófica dos normalianos 6 não é contraditória com uma orientação para a economia, como é possível constatar em relação aos dois sociólogos economistas durkheimianos, normalianos e mestres em Filosofia, Maurice Halbwachs e François Simiand ${ }^{7}$ - este último foi, aliás, nomeado professor de Economia no Conservatoire National des Arts et Métiers, a partir de 1923. Portanto, a formação intelectual não basta para dar conta das estratégias críticas.

Todavia, é plausível seguir essa pista mais além, interrogando-se acerca da natureza da relação com a Economia Política mantida pelos três sociólogos franceses. Aliada a uma formação inicial alheia à economia, essa relação não estaria na origem da estratégia de substituição?

Secretário de Henri Saint-Simon no momento de seu esforço para esclarecer as condições de surgimento e de estabilização da sociedade industrial, o jovem Comte vê-se encarregado, em agosto

6 Os normalianos são alunos da École Normale Supérieure ou dela egressos (nota do revisor da tradução).

7 Em outro quadro intelectual e histórico completamente distinto, é possível lembrar que a formação filosófica de Marx tampouco o impediu de voltar-se, muito profundamente, para o estudo da Economia Política e a sua crítica. 
de 1817, da reforma da Economia Política (GOUHIER, 1970, III, p.167, 189-198). Depois de um entusiasmo pela Biologia, Saint-Simon descobre na Economia Política o meio que ele procura desde 1802 para fundar a ciência social. Embora a Economia Política abra a via, ela não a sedimentou definitivamente, motivo pelo qual Saint-Simon reprova Say por não considerar devidamente a dimensão política da Economia Política. Ainda sob o encanto do "mestre", Comte propõe-se a essa missão e apresenta a sua reforma da Economia Política nas páginas de revistas efêmeras que ambos escrevem e em resenhas publicadas em 1828 (COMTE, 1970). Posteriormente, ele desenvolve-a em uma série de opúsculos, reimpressos nos anexos de seu Sistema de política positiva (COMTE, 1851-1854, IV, apêndice). Nesse ínterim, a reflexão de Comte desdobrou-se na severa condenação da $47^{\mathrm{a}}$ lição do seu Curso de filosofia positiva (COMTE, 1830-1842, II, p.92-97). No entanto, a informação de Comte é assaz limitada em matéria de Economia Política e isso se agrava uma vez que ele decide praticar uma "higiene cerebral", que consiste em não mais ler os seus contemporâneos. Todavia, observaremos uma interessante exceção naquilo que concerne à Economia Política, quando Comte comenta com John Stuart Mill a sua leitura do livro de Charles Dunoyer, De la liberté du travail (carta de Comte a Mill, fevereiro de 1845, em Comte \& Mill, 1899, p.409-411).

Por sua vez, o jovem Durkheim, ainda aluno da École Normale Supérieure, encontra a Economia Política quando trabalha em sua tese. Ele informa-se sobre aquilo que dizem os economistas a esse respeito, indo além da escola liberal francesa, por ocasião de sua viagem de estudos à Alemanha (1885-1886). Nessa viagem ele toma conhecimento da Economia Política de Schmoller, de Adolph Wagner, mas também daquela de Carl Menger. Entretanto, seu julgamento sobre o aporte científico da Economia Política é negativo por questões metodológicas profundas, conforme ele exprime no capítulo 2 d'As regras do método sociológico. Em meados dos anos 1890, Durkheim desinteressa-se da Economia, negligenciando quase completamente as diferenças doutrinais (STEINER, 2005, capítulo 1).

O encontro de Bourdieu com a Economia Política faz-se na prática aquando dos trabalhos por ele desenvolvidos na Argélia. É precisamente no contexto de uma sociedade colonial em plena 
efervescência política, a partir da qual Bourdieu avalia o alcance sócio-econômico das transformações impostas pelo poder colonial e, em seguida, pelo poder oriundo da luta armada, que ele desperta para as questões levantadas pela Economia Política (BOURDIEU, 1961; 1963; 1977a; BOURDIEU \& SAYAD, 1964). Essa abordagem lateral do assunto pode explicar a razão pela qual, inicialmente, a crítica da Economia Política é relativamente moderada no sentido de não fazer dos economistas um alvo particular da sua crítica mesmo se ele releva os erros que estes podem cometer devido à ignorância das realidades sociais. Não seria senão na última fase dos seus trabalhos que Bourdieu desenvolveria uma crítica sociológica radical da teoria econômica (BOURDIEU, 1995; 1997; 2000). O seu conhecimento dessa área é muito limitado, conquanto seja ele em parte compensado por um conhecimento da obra de Marx, cuja dimensão econômica desempenha certamente um papel essencial na construção da economia geral das práticas nos fundamentos da Sociologia de Bourdieu.

Os três sociólogos franceses têm, dessa forma, um conhecimento, na melhor das hipóteses, medíocre da Economia Política. Portanto, a violenta crítica seria a marca da sua ignorância? As coisas não são assim tão simples em razão de dois contra-exemplos que imediatamente vêm à mente. Professor de economia dentro de diferentes universidades norte-americanas, Thorstein Veblen elabora uma critica da Economia Política cuja intensidade nada deve àquela dos sociólogos franceses, conforme mencionado por Wesley C. Mitchell ao ler a obra de Simiand publicada em 1912 (GISLAIN \& STEINER, 1999, p.282-285). Do mesmo modo, Halbwachs e Simiand desenvolvem a crítica durkheimiana da economia, mostrando-se muito bem informados em matéria de Economia Política sem que isso os faça renunciar à estratégia de substituição de Comte e Durkheim ${ }^{8}$.

8 Poderíamos ser tentados a afirmar que o maior grau de informação de Simiand tenha-o levado a desfazer-se de sua crítica ao homo economicus, conduzindo-o a introduzi-lo como personagem em sua última grande obra (SIMIAND, 1932, II: 500-504). Isso é verdade, mas é difícil crer que essa evolução seja devida a um conhecimento ao qual Simiand não teria disponível em 1912. Por outro lado, mesmo considerando essa data tardia, Simand não tem de qualquer forma renunciado à estratégia de substituição da Economia Política. 


\section{A crítica metodológica da Economia Política}

Os três sociólogos dirigem duas críticas metodológicas à Economia Política: a primeira reprova aos economistas por isolarem os fatos econômicos dos outros fatos sociais; a segunda refere-se à natureza do homo economicus, esse personagem estranho que o economista põe em ação no isolamento por ele criado.

A condenação da postura que isola a economia do conjunto social é unânime ${ }^{9}$. Com o seu conceito de consenso social, Comte reivindica a existência de uma relação mútua entre os domínios funcionalmente separados da vida social. Reencontramos esse tema em Durkheim quando defende a contiguiidade entre as Ciências Sociais, a fim de lutar contra a anomia; igualmente o identificamos na obra de Bourdieu, por meio da idéia de conversão dos diferentes capitais

9 "É necessário, aliás, cuidadosamente acentuar que o reconhecimento geral de nossos economistas sobre o isolamento de sua pretendida ciência, relativamente ao conjunto da Filosofia social, constitui implicitamente um reconhecimento involuntário, decisivo mesmo que indireto, do vazio científico dessa teoria que Adam Smith não tinha concebido assim. Porque, pela natureza de seu sujeito, dentro dos estudos sociais como dentre todos aqueles relativos aos corpos vivos, os diversos aspectos gerais são, necessariamente, mutuamente solidários e racionalmente inseparáveis, ao ponto de não poderem ser convencionalmente esclarecidos a não ser uns pelos outros" (COMTE, 1830-1842, II, p.94). Um pouco depois, ele volta ao tema: "Todo o estudo isolado dos diversos elementos sociais é, então, pela natureza da ciência, profundamente irracional e deve permanecer essencialmente estéril, a exemplo de nossa economia política, fosse ela melhor cultivada (ibid, p.120) e Comte condena "todos aqueles que se esforçam hoje em depreciar o ainda em desvantagem sistema de estudos sociais, por uma imitação vulgar de um método que estuda a realidade 'aos pedaços', próprio às ciências inorgânicas” (ibid). Desde seus primeiros artigos em 1886 Durkheim designa "o grande erro dos economistas" pelo fato de verem apenas indivíduos isolados e justapostos: quer se queira ou não, que elas sejam para o bem ou para o mal, as sociedades existem. É no seio das sociedades constituídas que se manifesta a atividade econômica. A lógica nada pode contra um fato que complica, é verdade, os dados do problema, mas do qual não é possível fazer abstração" (DURKHEIM, 1970, p.208). Bourdieu concorda que a autonomia da teoria econômica é parcialmente fundada sobre a autonomia do campo econômico ele mesmo (BOURDIEU, 2000: 16-17)., mas, ele não aceita a ilusão desta separação "O objeto de uma verdadeira economia das práticas não é outra coisa que a economia das condições de produção e reprodução dos agentes e das instituições de produção e reprodução econômica, cultural e social, quer dizer, o objeto mesmo da sociologia na sua definição mais completa e mais geral (ibid, p.25-26). 
(econômico, cultural, social, simbólico). O consenso ou a interdependência, também eles estão na origem do "fato social total" que Mauss aplica ao salário e à moeda, estudados por Simiand.

Outrossim, a convergência entre os três sociólogos também é grande quando se trata de condenar o homo economicus, pois, ao rejeitar-se a autonomia da economia vis-à-vis o conjunto social, o personagem que deve assumir a ação (por tratar-se de um calculador consequiencialista infatigável da sua utilidade desejada) não tem sentido em tal isolamento. Comte percebe muito precocemente o surgimento deste personagem (apenas recém-batizado por Mill) de modo a rejeitar tal antropologia, procedimento no qual é seguido por Durkheim e Bourdieu ${ }^{10}$.

Uma vez descoberta a semelhança no âmbito da crítica metodológica, constata-se igualmente grande proximidade entre os três sociólogos na maneira pela qual eles pretendem constituir uma ciência social capaz de explicar a atividade econômica sem cair nos erros habituais da Economia Política. Três dimensões são mobilizadas: a histórica, a social (no sentido de relações outras que não aquelas típicas de um mercado povoado de agentes econômicos abstratos) e a política.

A referência à história significa uma contextualização dos fatos sociais (dentre os quais os fatos econômicos) e uma conside-

10 Comte releva esse ponto muito antes (1826), provavelmente baseando-se no utilitarismo francês das Luzes (HELVÉTIUS \& HOLBACH): "A fisiologia do século XIX, confirmando ou antes explicando a experiência universal, demonstrou positivamente a frivolidade dessas teorias metafísicas que apresentam o Homem como um ser essencialmente calculador movido apenas pelo objetivo do interesse pessoal" (COMTE, 1851-1854, IV, p.209, ver também Comte 1830-1842, I, p.856 e II, p.447, 455). Durkheim rejeita a idéia de "reduzir a sociedade a nada mais que uma simples justaposição de indivíduos” (DURKHEIM, 1970, p.208, 212). Eliminando isso que faz a solidariedade social, a teoria econômica "criou integralmente um ser da razão. Por ora, o Homem e a sociedade que concebem os economistas são pura imaginação que na realidade não corresponde a nada" (ibid., p.212). Assim, resta na mão dos economistas apenas "o triste retrato do ser egoísta em si” (ibid., p.85). Para Bourdieu, o homo economicus é um monstro antropológico (1997ạ, p.256), porque o espírito é socialmente estruturado, assim como a conduta econômica (ibid., p.259-260). 
ração das formas por meio das quais se processa a vida social ${ }^{11}$. A história presta-se a contextualizar o objeto de estudo, apreendê-lo intelectualmente - procedimento complexo, em virtude da complexidade do social. Essa convergência acontece, embora as visões da história difiram sensivelmente. A Sociologia de Comte, reprovada por Durkheim, funda-se em uma filosofia da história, conduzindoo, sobretudo, a interessar-se pela dinâmica social - a lei dos três estados - e nada é proposto, a não ser uma única lição (a $\left.50^{\mathrm{a}}\right)$, sobre a estática, no Curso de filosofia positiva ${ }^{12}$. Em contrapartida, Durkheim e Bourdieu desenvolvem análises refinadas dos mecanismos sócio-econômicos graças às quais lhes é possível considerar o funcionamento preciso de certas instituições econômicas da sociedade moderna (a divisão do trabalho ou as corporações de ofício em Durkheim, a relação com o tempo e a atividade ou os gostos em Bourdieu). A historicidade não os leva a negligenciar a análise detalhada das relações sócio-econômicas.

A dimensão social da atividade econômica é evidenciada quando se trata de caracterizar as relações econômicas: mas há notáveis diferenças segundo a importância conferida às relações de produção capitalistas, haja vista que estas últimas diferem daquelas da sociedade industrial consideradas como parâmetro por Augusto Comte e Durkheim. O social é então analisado por intermédio de uma antropologia na qual se enfrentam as tendências egoístas e altruístas dos seres humanos, em Comte, Durkheim e Mauss; em

11 Dando continuidade à sua crítica da Economia Política, Comte insiste sobre o marco histórico indispensável à constituição da Sociologia, daí seu enunciado "sobre a preponderância histórica do método sociológico" (COMTE, 1830-1842, II, p.100, ver também o fim da $48^{\mathrm{a}}$. lição). As citações precedentes de Durkheim mostram que ele também encara a história como um ingrediente indispensável da Sociologia Econômica: toda a obra de Simiand é uma ilustração disto com os seus trabalhos sobre as flutuações de longa duração, as evoluções do salário ou os trabalhos sobre a regulação monetária nos Estados Unidos (STEINER, 2005, cap. 4). Confrontado com as condições próprias ao contexto econômico argelino, Bourdieu é sensível à importância da dimensão histórica (BOURDIEU, 1963, passim; 2000, p.12-15). O conceito de habitus está encarregado de reunir a prática e a história, de tal maneira que se torna possível pela abordagem sociológica "devolver a economia à sua verdade de ciência histórica" (1997a, p.266).

12 É necessário notar, entretanto, que todo o volume II do Sistema de política positiva, de 1852, é dedicado à Estática Social (N. R. T.). 
Bourdieu essa análise acontece, antes e sobretudo, por meio de uma dimensão de dominação. Contudo, encontra-se também na obra de Bourdieu uma reflexão aprofundada e constante sobre o "desinteresse" e o "dom" nas relações sociais, mas para nelas realçar as aporias, e, finalmente, o caráter "interessado" do comportamento "desinteressado", mediante a teorização das noções de capital e de trocas simbólicas (BOURDIEU, 1971; 1977b, 1994) ${ }^{13}$.

Há, entretanto, uma sensível diferença entre os três sociólogos no tocante à dimensão política. Fortemente influenciado pela obra de Marx, Bourdieu não concebe o social independentemente de tal dimensão, o que falta em Comte e Durkheim, conquanto exista interesse do primeiro por essa questão, porque, à imagem de Saint-Simon, ele busca estabilizar a sociedade francesa após uma fase crítica e revolucionária, dominada política e culturalmente por categorias desde então ultrapassadas ${ }^{14}$. À exceção dos momentos mais científicos d'As regras do método ${ }^{15}$ e das reflexões apresentadas nas suas lições (DURKHEIM, 1998-1900), Durkheim não atribui especial importância à dimensão política em sua Sociologia.

Em que pese uma possível simplificação, as posições dos três sociólogos estão resumidas no quadro seguinte, distinguindo, por um lado, a dimensão metodológica propriamente dita (a abstração

13 Esse ponto exigiria ser desenvolvido pelo estudo da oposição feita por Augusto Comte entre o egoísmo e o altruísmo, das reflexões de Durkheim sobre a educação moral (notadamente a dimensão do "pertencimento ao grupo"), das reflexões sutis de Mauss (1925) e de Maunier (1927) sobre o dom e depois daquelas de Bourdieu sobre a economia da honra e as trocas simbólicas (BOURDIEU, 1971; 1977b; 1994; 1997b).

14 A Sociologia é uma obra política, segundo Comte, o qual vê uma ligação essencial entre a ciência e a ação política, a primeira devendo permitir concluir a Revolução, estabilizar os espíritos e a vida coletiva (COMTE, 1830-1842, I, p.38-39). A denúncia da formação essencialmente literária e orientada ao jogo verbal dos advogados é um índice bem conhecido (ibid, II, p.93). A Sociologia de Bourdieu repousa sobre o conceito de campo, que é estruturado pela oposição entre dominantes e dominados. Na última parte de sua obra, Bourdieu insiste sobre a dimensão ideológica da teoria econômica, "ciência de Estado" (BOURDIEU, 2000, p.22), dimensão que participa da difusão da vulgata liberal (ibid, p.149) e de suas consequiências políticas contra as quais Bourdieu (1998) manifestou-se com violência.

15 Pense-se no capítulo 3 sobre o normal e o patológico e a ação do legislador sobre o patológico. 
e o isolamento da Economia Política) e, por outro lado, a própria crítica (considerando a história, o social, a política e as representações). Para oferecer uma dimensão comparativa, o lado direito do quadro indica as posições de Marx, Pareto e Weber. Não se justifica aqui em detalhe as posições atribuídas aos três autores, assunto que foi objeto de trabalhos anteriores (GISLAIN \& STEINER, 1995; STEINER, 2000; 2005, cap. 7).

Quadro 1 - Tipos de crítica da Economia Política

\begin{tabular}{|l|ccc|ccc|}
\hline & Comte & Durkheim & Bourdieu & Marx & Pareto & Weber \\
\hline \multicolumn{1}{|l|}{ Crítica voltada para: } \\
\hline $\begin{array}{l}\text { - o método abstrato } \\
\text { - a posição da Eco- } \\
\text { nomia Política nas } \\
\text { Ciências Sociais }\end{array}$ & $\operatorname{Sim}$ & $\operatorname{Sim}$ & $\operatorname{Sim}$ & Não & Não & Não \\
\hline $\begin{array}{l}\text { Crítica que considera: } \\
\text { - a história }\end{array}$ & $\operatorname{Sim}$ & $\operatorname{Sim}$ & $\operatorname{Sim}$ & $\operatorname{Sim}$ & Não & Sim \\
- o social & $\operatorname{Sim}$ & $\operatorname{Sim}$ & $\operatorname{Sim}$ & $\operatorname{Sim}$ & $\operatorname{Sim}$ & $\operatorname{Sim}$ \\
- a política & $\operatorname{Sim}$ & Não & $\operatorname{Sim}$ & $\operatorname{Sim}$ & $\operatorname{Sim}$ & Nim \\
\hline
\end{tabular}

O quadro mostra a grande homogeneidade dos três sociólogos franceses no tocante à Economia Política; excetuando-se a política, cujo impacto não é considerado por Durkheim, a homologia é completa nos outros três pontos. Além disso, a diferença com as outras formas de crítica da Economia Política é notável: nem Marx, nem Pareto, nem Weber opõem-se à abstração no âmbito da Economia Política, inclusive o homo economicus, e nenhum dentre eles sugere questões de princípio quanto à legitimidade do isolamento da Economia Política, embora esse isolamento não seja, obviamente, senão uma fase da pesquisa. Em contrapartida, quando o assunto são os meios pelos quais a crítica procede, os seis autores aproximam-se. A única particularidade refere-se à importância atribuída por Pareto à história, não considerada pelo autor como um meio particularmente potente para avançar em economia ou Sociologia, embora Pareto empenhe-se em explicar 
os fatos empíricos, tal qual se observa nos dois últimos capítulos do seu Traité de Sociologie générale. Weber, por sua vez, confere à historia uma relevância muito mais significativa e, faz dela um dos objetivos da sua Sociologia Econômica, como acima exposto.

Essa primeira possibilidade de caracterização da crítica sociológica à economia pode ser aprofundada por meio do exame da forma pela qual os três sociólogos franceses traduzem a sua posição metodológica para desenvolverem uma Sociologia do conhecimento econômico.

\section{A Sociologia do conhecimento econômico}

A crítica sociológica da economia na obra de Durkheim e dos durkheimianos caracteriza-se pela importância atribuída às representações sociais no funcionamento da economia. Os durkheimianos consideram dois tipos de representações econômicas: as representações espontâneas que derivam do próprio funcionamento da atividade econômica ${ }^{16}$ - as representações populares dos preços estudadas por Halbwachs (1912) ou aquelas relativas à moeda, por Simiand (1934) - e as representações construídas provenientes de uma instituição particular (o sistema escolar) ou de organizações (aquelas em que atuam os "peritos" ["experts"], os "técnicos da organização econômica", os "prescritores" ${ }^{17}$ ) encarregadas da difusão de diversas formas de saber econômico. Uma vez consideradas as representações econômicas construídas, a sua ação sobre os comportamentos dos atores - os objetos mesmos dessas representações - insere-se na crítica sociológica da economia. Trata-se justamente daquilo que Pierre Bourdieu (1984a; 1987) denominou de "efeito de teoria”. No âmbito da Sociologia do conhecimento econômico, um efeito de teoria designa a situação em que a construção intelectual (a teoria econômica), ao descrever o mundo econômico, modifica a percepção desse mundo social pelos atores, assim como os seus

16 O exemplo mais conhecido nessa época é aquele do fetichismo da mercadoria (MARX, 1867) e devido ao fetichismo da moeda no mundo, ainda embrionário, da finança (MARX, 1861-1863, III, p.535s).

17 No original, "prescripteurs", ou seja, aqueles que prescrevem práticas ou políticas econômicas específicas (N. R. T.). 
comportamentos, de tal modo que a teoria produz ou "performa" (CALLON, 1998) a realidade que ela pretende descrever.

Se retomarmos os seis autores e compararmo-los sob o registro da Sociologia do Conhecimento, pode-se evidenciar a existência de uma tradição intelectual específica à essa tradição crítica considerada aqui.

Quadro 2 - crítica da economia política e sociologia do conhecimento econômico

\begin{tabular}{|l|ccc|ccc|}
\hline A crítica considera: & Comte & Durkheim & Bourdieu & Marx & Pareto & Weber \\
\hline $\begin{array}{l}\text { As representações } \\
\text { espontâneas }\end{array}$ & Não & $\operatorname{Sim}$ & $\operatorname{Sim}$ & $\operatorname{Sim}$ & $\operatorname{Sim}$ & $\operatorname{Sim}$ \\
$\begin{array}{l}\text { As representações } \\
\text { construídas }\end{array}$ & $\operatorname{Sim}$ & $\operatorname{Sim}$ & $\operatorname{Sim}$ & Não & Não & Não \\
Os efeitos de teoria & Não & $\operatorname{Sim}$ & $\operatorname{Sim}$ & Não & Não & Não \\
\hline
\end{tabular}

À exceção de Comte, todos os autores consideram, de uma forma ou de outra, as representações espontâneas. Estas últimas figuram entre os recursos necessários aos atores para orientarem-se na prática no mundo econômico e, a esse título, elas são teoricamente importantes para uma crítica da Economia Política que faz valer a importância do social, da história e da política. Mas a situação modifica-se com as representações construídas, consideradas apenas pelos três sociólogos franceses.

Em consequiência, o papel da educação na vida social adquire grande importância, pois, embora ela desempenhe um papel central na obra de Comte, de Durkheim e de Bourdieu, esse não é o caso de Marx, de Pareto e de Weber. Quando Marx interessa-se pelo sistema universitário, mais amplamente voltado na Alemanha que alhures ao ensino da Economia Política, ele qualifica-o como o lugar por excelência da pia das economias rasteiras, a economia professoral, segundo ele representada por Wilhelm Roscher (MARX, 1861-1863, III, p.590-591). Pareto jamais estudou em detalhe a instituição escolar e Weber a ela não se refere senão por alusão, excetuando-se o seu trabalho sobre o ethos dos mandarins chineses 
no seu Confucionismo e Taoísmo (WEBER, 1915) - porém, neste caso as representações econômicas não têm importância alguma, pois esse ethos é caracterizado pelo seu conteúdo estético e literário.

Compreendida como meio de difusão dos conhecimentos e das representações adequadas à formação de um cimento intelectual comum entre os membros da sociedade industrial, a educação representa um ponto essencial da concepção de sociedade na obra dos três sociólogos franceses. A crítica da economia pode negligenciar a educação quando ela dirige-se aos virtuosi da racionalização do conhecimento; entretanto, isso deixa de ser o caso desde que se considere a Economia Política como um fato social - em outros termos, como um modo de fazer, pensar e sentir, corrente na sociedade, graças ao qual o indivíduo moderno concebe o mundo social e nele transita. Neste caso, a difusão das representações construídas ou científicas torna-se tão central quanto as representações espontâneas engendradas pelas relações econômicas.

A reforma moral dos indivíduos é uma dimensão essencial do projeto de Comte (1851-1854, II, cap. 4-5 e IV, p.257-272); para isto, a educação desempenha um papel considerável na qualidade de meio para contrabalançar os efeitos do discurso econômico, quando se trata da oposição entre egoísmo e altruísmo. Aliás, essa é a razão pela qual ele aprecia a obra de Dunoyer, conquanto esta possua as falhas próprias aos economistas ${ }^{18}$. Com efeito, na obra De la liberté du travail, Dunoyer faz a distinção entre duas grandes categorias de atividade produtivas, se versam sobre as coisas ou sobre as pessoas, colocando forte ênfase sobre esta última catego-

18 "Mesmo que oriundo do seio da economia, o sr. Dunoyer realizou um grande esforço numa direção mais sadia, por sua notável distinção entre os dois tipos de arte, agindo algumas sobre as coisas e outras sobre os homens, e por criticar fortemente a Economia Política de tratar até agora apenas das primeiras. Sua reabilitação da concorrência e sua vigorosa crítica das pretendidas organizações do trabalho, comuns no momento atual, adquiram, receio eu, um caráter totalmente absoluto, tendendo talvez a censurar indefinidamente toda verdadeira sistematização industrial; mas como ele insiste muito acerca da necessidade de reformar as populações antes de [reformar] os governos, penso que sua influência efetiva, muito embora haja um vício essencial de concepção, será finalmente muito útil no meio atual [...]" (Comte a Mill, carta de 28.2.1845, in: COMTE \& MILL, 1899, p.411; ver também a carta de 15.5.1845, ibid., p.421-423). 
ria (DUNOYER, 1845,1 $x$-xi e III, liv. IX). Essa perspectiva está contemplada nas posições de Comte (1851-1854, II: 319); no entanto, essa etapa de sua reflexão sofre com a ausência de um estudo das representações espontâneas. Os desenvolvimentos de Comte em Sociologia do conhecimento econômico permanecem limitados: a sua abordagem guarda um alto nível de generalidade, acentuado pelo caráter messiânico, que confere à sua reflexão a insistência com respeito à nova religião - a Religião da Humanidade - e o fato de a educação ser confiada ao "sacerdócio positivista".

Por outro lado, Durkheim e os durkheimianos reuniram os três ingredientes da Sociologia do conhecimento econômico próprios à tradição intelectual em questão: o sistema escolar, as representações econômicas espontâneas e as representações construídas. O papel do sistema escolar é estudado minuciosamente por Durkheim no processo de constituição do indivíduo moderno (Durkheim, 1904-1905) e na educação moral (DURKHEIM, 1902-1903). Porém, ele trata pouco da Sociologia do conhecimento econômico (STEINER, 2005, p.87-89), o que nada surpreende tendo em vista seu afastamento da Economia Política ao final dos anos 1890.

Os durkheimianos desenvolverão esse argumento na sua Sociologia Econômica. Halbwachs avança nessa direção no momento em que comenta a obra de Pareto. Segundo Halbwachs (1938, p.132-134), na sua análise das ações lógica e não-lógica, Pareto explorou a lógica afetiva, ou lógica do sentimento e da crença. Halbwachs interessa-se particularmente pela ação não-lógica, na qual existe um alvo subjetivo, mas não um alvo objetivo, visando a interpretá-la como uma ação cuja lógica é reconhecida no grupo, porém não além dele. Esse argumento aplica-se ao pensamento científico: as regras de demonstração dos matemáticos, a ciência experimental dos físicos, todas elas são, modos de pensar próprios a grupos sociais que alcançaram a sua autonomia a partir do desenvolvimento da ciência. Halbwachs sugere existirem várias outras lógicas coletivas, tais como aquelas dos padres e dos juristas ${ }^{19}$.

19 Halbwachs leva em conta a formação dos formadores ou dos peritos na conclusão de uma série de cursos dados no Instituto Solvay em 1938: "Mas os cientistas, de onde nos parece proceder todos esses movimentos do pensamento 
Pode causar espanto que Halbwachs não tenha buscado aplicar aos economistas essas reflexões sobre as lógicas dos valores e das instituições que as suportam.

Coube a Simiand o papel principal. Na linha da crítica metodológica de Durkheim, ele qualifica como escolástica a tendência de os economistas considerarem aquilo que satisfaria o espírito de um economista como suficiente ao espírito de todo indivíduo leigo. A escolástica assimila a razão sábia e aquela da prática cotidiana porque ambas representam as duas faces da racionalidade instrumental: a racionalidade teórica, com a qual o teórico raciocina e fornece as suas provas diante dos seus pares, e a racionalidade prática, graças à qual o ator econômico age ou agiria caso tivesse boas informações e boas competências cognitivas. Faz-se, então, necessário seguir Simiand nos seus estudos sobre a moeda e as finanças, para acompanhar o desenvolvimento desse tema de reflexão. Questionado acerca da pertinência das grandezas nominais - aquelas sobre as quais se apóia o seu trabalho sobre o salário (Simiand, 1932) - comparativamente às grandezas reais, Simiand admite como possibilidade as situações em que os trabalhadores não defenderiam mais o salário nominal, na condição em que a baixa deste último estivesse acompanhada por uma baixa de preços, condição que não comprometeria seu poder de compra. Esse exemplo tem como origem uma modificação das representações econômi$\operatorname{cas}^{20}$ : Simiand interpõe a posição defendida pelos economistas, provavelmente no debate público, e confere-lhes a capacidade de modificarem as representações e os comportamentos dos atores.

público, da opinião sobre a ciência, não foram, em geral, formados sozinhos. Esses profissionais saíram de escolas, eles trabalharam em laboratórios, em bibliotecas, viveram nos meios científicos, aproveitando todo um conjunto de instituições que objetivam formar e manter distintas de todas as outras e satisfazendo, com sua linguagem, suas convenções, suas tradições também, algo que poderia ser nomeado como sociedade dos cientistas" (HALBWACHS, 1955, p.230-231).

20 “.... Se isto [uma luta operária empreendida em termos de manutenção do poder de compra e não simplesmente do salário nominal] produz-se em certa medida, é talvez lá onde economistas ou pensadores muito simplistas confundiram as idéias espontâneas das pessoas, fazendo crer na justiça e virtude de sistemas de escala móveis dos salários segundo o preço de consumo" (SIMIAND, 1934, p.83). 
Desse modo, emerge um efeito de teoria, no sentido de que a teoria econômica influencia os comportamentos dos indivíduos, porque, ao ter alterado os quadros com os quais os últimos percebem o mundo econômico, os comportamentos são também e na mesma medida modificados.

Simiand retorna ao assunto na sua obra sobre o salário: qual seria o "justo salário", pergunta ele (SIMIAND, 1932a, II, p.534)? Se levarmos em conta a realidade, em lugar de acreditarmos na formação desta pelos conceitos e pela vontade individual, o salário então justo seria o salário conforme o Direito Econômico e a moral cataléctica que o acompanha:

Assim, nas nossas sociedades de economia ocidental contemporânea, o salário justo tanto quanto o preço justo será, nesse sentido, aquele resultante da plena aplicação dos princípios do Direito Econômico que essas sociedades adotaram; em outras palavras, princípios denominados liberdade de produzir, liberdade de consumir, liberdade de trabalhar ou não trabalhar, de contratar ou não, livre concorrência; a partir daí, parece-nos que se busca, às vezes longe e de modo complexo, a prova de que sob esse regime, conquanto suficientemente aplicado, a remuneração do operário é exatamente aquela que lhe é devida segundo esse regime, do mesmo modo que o preço de um produto é exatamente aquele que, de acordo com esse regime, é direito do produtor (ibid., p.535).

Simiand aqui introduz elementos novos, fazendo intervir o Direito Econômico, um fenômeno decisivo, com a inscrição social da teoria nas instituições (o Direito) e, implicitamente, na formação econômica das pessoas, cuja função reside em elaborar esse Direito, seguido de sua aplicação. Trata-se, então, da questão do conhecimento econômico dos peritos e dos seus efeitos sociais.

Simiand aborda essa questão em vários momentos. Em suas lições sobre o taylorismo, ele destaca o papel dos efficiency engine$e^{21}{ }^{21}$ que estabelecerá fórmulas de cálculo dos salários nas quais o bônus deveria incitar os operários a um acréscimo de esforço (SIMIAND, 1929-1931, II, lição 7). Com o perito em economia e o

21 No original, em inglês: "engenheiros da eficiência” (N. R. T.). 
engenheiro racionalizador, observa-se o estabelecimento concreto das instituições e dos comportamentos suscetíveis de produzirem um efeito de teoria. Essa dimensão cognitiva da atividade econômica reaparece por ocasião de seu último curso no Collège de France, quando Simiand estuda o ciclo curto dos negócios e volta sua atenção para o mercado financeiro. A importância atribuída à perícia econômica provém tanto do confronto dos agentes econômicos com os movimentos de opinião sobre o futuro quanto das suas decisões, reflexos das crenças quanto a esse futuro. Socialmente circunscritas a um círculo limitado, essas crenças impõem-se a todos os atores econômicos por meio do valor da moeda e dos títulos que objetiva a crença social sobre o futuro (SIMIAND, 1937, p.6). Esse mecanismo sócio-econômico atualiza-se por intermédio de numerosas transações econômicas; porém, a sua especificidade consiste em fundarse em estimativas (ibid, p.9-11). A dimensão cognitiva da atividade econômica e a perícia econômica tornam-se, então, decisivas para definir a referência com a qual os agentes coordenar-se-ão em torno de uma crença comum, que, assim, torna-se auto-realizadora.

A abordagem retomada e radicalizada na última parte dos trabalhos de Bourdieu (1994; 2000), quando a questão é a escolástica econômica ${ }^{22}$ e o sistema escolar, um domínio essencial de sua Sociologia geral. Entre seus alunos, como Frédéric Lebaron (2002; 2003), a aproximação com o simbólico e o sistema escolar assegura uma verdadeira continuidade com a abordagem durkheimiana. A economia é considerada uma crença, tal qual uma crença religiosa, e o estatuto de produtor de crença econômica depende da autoridade no campo econômico; esta última sendo fundada sobre a natureza e o volume dos capitais científicos e simbólicos em poder do agente. Elevada ao estatuto de "substituto laicizado da fé religiosa" (LEBARON, 2000: 7, 244), essa crença está no fundamento da ordem simbólica, justificando instituições essenciais como a exemplo dos

22 Essa expressão está próxima daquilo que Bourdieu define como falácia escolástica (scholastic fallacy) pelo fato de "inserir o metadiscurso ao princípio do discurso, metaprático ao princípio das práticas” (Bourdieu, 1994: 219); a teoria econômica da escolha racional é o próprio exemplo dessa scholastic fallacy (ibid.: 222). Sobre a aproximação entre Simiand e Bourdieu, pode-se também consultar a tese de livre-docência de Lebaron (2003, cap. 1). 
bancos centrais, pela via da competência ou da neutralidade dos profissionais e dos peritos que neles operam (ibid, cap. 6). Todavia, para que esse papel de legitimação simbólica seja eficaz, é necessário ainda que a crença econômica seja amplamente difundida. Lebaron, para tanto, examina o ensino da economia oferecido na Escola Nacional de Estatística e de Administração Econômica (ENSAE) (ibid, cap. 3) ${ }^{23}$, assim como os esforços realizados no período imediatamente posterior à II Guerra Mundial para difundir a cultura econômica junto ao grande público, dentro de um objetivo tecnocrático estreitamente ligado ao esforço de reconstrução e de planificação à francesa (DUVAL, 2004; STEINER, 2005, cap. 4). A Economia Política ortodoxa é uma crença sem fundamento científico e, a esse título, ela deve ser ultrapassada por uma Sociologia Econômica cientificamente fundada ${ }^{24}$. Além disso, retornando à

23 A interrogação sobre a natureza do ensino existe alhures, especialmente nos Estados Unidos (Klamer e Colander, 1990; Colander, 2005), muito embora a natureza e os objetivos da interrogação sejam muito diversos, voltados nesse país para o aprimoramento da pedagogia do ensino econômico (menos pela técnica e mais estreitamente voltada para os dados empíricos) antes do que para sua crítica (Colander, 2005: 197-198); apesar de que esta última seja virulenta no movimento denominado Post-Austistic Political Economy.

24 Bourdieu tem uma posição mais ambígua que a de Lebaron quando o assunto é a relação da economia com a realidade. O problema é o da natureza da crença econômica: se se trata do resultado das lutas simbólicas entre os teóricos, daí qualquer crença pode surgir. Ora, em várias ocasiões, Bourdieu deixa transparecer sua hesitação sobre esse ponto crucial, fazendo intervir a adequação da teoria à realidade. Desse modo, a propósito da teoria de classes em Marx, ele escreve que essas classes podem existir graças a um trabalho político, "que possui tanto mais chances de ser bem-sucedido quanto mais armado estiver com uma teoria bem fundada na realidade e, portanto, mais capaz de exercer um efeito de teoria" (BOURDIEU, 1987: 154; sem grifos no original). Um pouco mais adiante, ele retoma essa idéia, ligando o capital simbólico - conceito particularmente operante no campo científico - ao efeito de teoria: "..../A eficácia simbólica depende do grau do efeito da teoria. Ele é tanto mais poderoso quanto mais a teoria é adequada. O poder simbólico é um poder de fazer coisas por meio de palavras. E somente se ela é verdadeira, o que significa dizer adequada às coisas, que a descrição realiza as coisas (ibid: 164; sem grifos no original). Estabelecendo assim a relação entre efeito de teoria, capital simbólico e a adequação à realidade, Bourdieu permite pensar que a "crença econômica" estabelece uma relação com o "verdadeiro", sem que saibamos exatamente a que ele faz referência nessa discussão, isto é, sem que se saiba a natureza desse "verdadeiro" ou dessa "adequação", nem a natureza do processo de luta no campo científico que lhe permite chegar a tal conclusão. 
abordagem de Marx, teórico da ideologia, o saber desqualificado não é ele mesmo menos considerado como politicamente perigoso (BOURDIEU, 1998; LEBARON, 2003b), dado que está suscetível de ter efeitos políticos com a difusão das categorias econômicas como categorias de apreensão do mundo social e como sistema simbólico justificando a dominação existente na ordem social estabelecida.

\section{Conclusão}

A estratégia seguida por Comte, Durkheim e Bourdieu pretende desqualificar e substituir a Economia Política por um saber verdadeiramente científico, a Sociologia ou a Sociologia Econômica. Essa estratégia repousa sobre um questionamento dos fundamentos metodológicos da Economia Política e sobre uma grande importância atribuída, pelos três, à Sociologia do conhecimento econômico, abordagem que se mantém sempre muito presente na Sociologia Econômica contemporânea de língua francesa (HEILBRON, 2001).

No entanto, existem diferenças importantes no modo de considerar as representações econômicas. Em uma análise que vai de Comte a Durkheim e aos durkheimianos, passando em seguida por Bourdieu, a articulação entre as representações espontâneas e as representações construídas fez emergir o efeito das teorias sobre aquilo que elas pretendem descrever. Todavia, há duas vias distintas para a pesquisa nesse domínio. Na primeira via, seguida por Durkheim e Bourdieu, é o sistema escolar e o seu modo de funcionamento que serve de ligação concreta entre as teorias e os atores. Na segunda, da qual visualizamos um prenúncio mediante a análise do Direito Econômico na obra de Simiand, a teoria econômica interfere no funcionamento econômico pelo intermédio dos dispositivos materiais ou das "tecnologias invisíveis" nos quais a teoria é incorporada (CALLON, 1998; CALLON \& MUNIESA, 2003). A reflexão passa, então, por uma Sociologia da Ciência e da Técnica muito mais que por uma Sociologia do sistema escolar e por uma pesquisa sobre as formas materiais de inscrição da teoria econômica na sociedade do que por uma pesquisa sobre os fundamentos simbólicos da dominação. Nesse sentido, a teoria da "performatividade" da ação econômica pela teoria econômica pertence a uma longa tradição de 
crítica sociológica da economia, tradição da qual ela explora, com energia e originalidade, um novo caminho, que contempla o efeito da inscrição da teoria em dispositivos, de modo a possibilitar aos atores "performar" a teoria sem a ter aprendido ${ }^{25}$. Entretanto, não deixaremos de considerar o fato segundo o qual, graças à tese da "performatividade", a Sociologia contemporânea do conhecimento econômico prolonga e altera significativamente a crítica da Economia Política: esta última não é mais desqualificada em razão dos seus erros metodológicos, mas é apresentada não como um saber descritivo dos processos sociais, mas como uma retórica prescritiva destes últimos, de maneira tanto mais eficaz quanto a prescrição estiver enraizada nos próprios dispositivos de mercado.

Finalmente, para abarcar a dinâmica própria dessa tradição crítica da Economia Política, seria necessário estudar metodicamente a sua face positiva, ou seja, a sequiência que, partindo das reflexões de Comte sobre o altruísmo, passa pelo pertencimento ao grupo, de Durkheim, para ser reformulada em termos do dom por Mauss e Maunier, antes que Bourdieu traga o conceito de "troca simbólica". Tal estudo permitir-nos-ia uma visão mais completa dessa tradição sociológica de crítica da Economia Política, desvendando como a pesquisa dos princípios de um comércio entre os seres humanos, não redutível ao comércio sob a sua forma mercantil, confere sentido à vertente crítica aqui abordada.

\section{Referências}

AIMARD, G. Durkheim et la science économique. Paris: Presses universitaires de France, 1962.

BOUDON, R. Le juste et le vrai. Études sur l'objetivité des valeurs et de la connaissance. Paris, Fayard, 1995.

25 Não me é possível desenvolver a contento esse ponto no espaço deste artigo; permito-me assim sugerir aos leitores um outro texto cuja última parte é precisamente consagrada a distinguir as duas formas de Sociologia do conhecimento econômico, segundo passam pelo ensino ou pelos dispositivos materiais (STEINER, 2008). 
. Au-delà du 'modèle du choix rationnel. In: SAINT-SERNIN, B. et alii. Les modèles de l'action. Paris: Presses Universitaires de France, 1998.

. Utilité ou rationalité ? Rationalité restreinte ou générale? Revue d'Économie Politique. 112 (5), 2002.

BOURDIEU, P. Sociologie de l'Algerie. Paris: Presses Universitaires de France, 1965.

. La société traditionnelle. Attitude a l'égard du temps et conduite économique. Socilogie du travail. 5(1), 1963. 22,1971

. Le marché de biens symboliques, L’Année sociologique,

Algérie 60. Structures économiques et structures temporelles. Paris: Minuit, 1977a.

. La production da la croyance. Contribution à une économie des biens symboliques. Actes de la recherche en science sociales. 13, 1977b. 1979.

. La Distinction. Critique sociale du jugement. Paris: Minuit, . Le sens pratique. Paris: Minuit, 1980. . Homo academicus. Paris: Minuit, 1984a. . Réponses aux économistes. 0Economia, 10, 1984b.

. Choses dites. Paris: Minuit, 1987. 994.

. Raisons pratiques. Sur la theorie da l'action. Paris: Seuil, . Le champ économique. Actes de la recherche en science sociales. 119, 1997a.

. Meditations pascaliennes. Paris: Seuil, 1997b.

. Acts of resistance. Against the Tyranny of the market, trad. Anglaise, New York: The New York Press, 1998.

. Les sctructures sociales de l'économie. Paris, Seuil, 2000.

BOURDIEU, P. \& SAYAD, A. Le déracinement. La crise de l'agriculture traditionnelle en Algérie. Paris: Minuit, 2004. 
BOYER, R. L'anthropologie de Pierre Bourdieu. Actes de la recherche en science sociales, 150, 2003.

. Une théorie du capitalisme, est-elle possible?. Paris: Odile Jacob, 2004.

BROCHIER, $\mathrm{H}$. La valeur heuristique du paradigme sociologique. Oeconomia, 10, 1984.

CAILLÉ, A. La sociologie de l'intérêt est-elle intéressante?. In: Caillé, A, 1986, Splendeurs et misères des sciences sociales. Genève, Droz, 101-116, 1981.

. Esquisse d'une critique de l'economie générale de la pratique, In: Lectures de Pierre Bourdieu, Cahiers du LASAR, 8-9, 103-213, 1988.

CALLON, M. Introduction: The embeddedness of economic Market in Economics, In: CALLON, M. (Ed.) The laws of the market. Cambridge: Blackwell, 1998.

CALLON, M. \& MUNIESA, F. Les marchés économiques comme dispositifs colletifs de calcul. Reseaux. 122, 2003.

COLANDER, D. The making of an economist Redux, Journal of Economic Perspectives, 19 (1), 2005.

COMTE, A. Cours de philosophie positive. Paris: Hermann, 1975. . Système de politique positive ou traité de sociologie instituant la riligion de l'humanité. 3 ed. Paris: Larousse, 1890. 1970. . Auguste Comte: Écrits de jeunesse. Paris \& La Raye: Mouton,

COMTE, A. \& MILL, J-S. Lettres inédites de John Stuart Mill à Auguste Comte publiées avec les réponses de Comte. Paris: Alcan, 1899.

CUSIN, F. \& BENAMOUZIG, D. Économie et Sociologie. Paris: Presses Universitaires de France, 2004.

DARBEL, A. et alii. Travail et travailleurs en Algerie. Paris: Mouton, 1964.

DUNOYER, C. De la liberté du travail. Paris: Guillaumin, 1845.

DURKHEIM, E. De la division du travail sociale (1893). Paris: Presses Universitaires de France, 1973. 
. Règles de la méthode sociologique (1894). Paris: Presses Universitaires de France, 1977.

. Leçons de sociologie. Physiologie du droit et des moeurs (1898). Paris: Presses Universitaires de France, 1969. 1974.

. Léducation morale. Paris: Presses Universitaires de France,

. L'évolution pédagogique en France (1904-5). Paris: Presses Universitaires de France, 1969.

. La science sociale et l'action. Paris: Presses Universitaires de France, 1970.

. Textes. Paris, Minuit, 1975.

DUVAL, J. Critique de la pensée journalistique. Le transformations de la pensée economique en France. Paris: Seuil, 2004.

FACCARELO, G. \& STEINER, P. Interest, Sensationism and Science of the legislator. French, Philosophie Économique, 1695-1830. European Journal of the History os Economic Thought, à paraître, 2008.

FAVEREAU, O. L'économie du sociologue ou penser (l'orthodoxie) à partir de Pierre Bourdieu, In: LAHIRE, B. (Ed.) Le travail sociologique de Pierre Bourdieu, dettes et critiques. Paris: La Découverte, 2001.

FOUCAULT, M. Sécurité, territoire, population. Paris: GallimardSeuil, 2004.

. Naissance de la biopolitique. Paris: Gallimard-Seuil, 2004.

GISLAIN, J.J. \& STEINER, P. La sociologie économique (1890 - 1920): Durkheim, Pareto, Shumpeter, Simiand, Veblen et Weber. Paris: Presses Universitaires de France, 1995.

. American Institucionalism and French Positive Political Economy: Some conections. History of Political Economy, 31(2), 1999.

GOUHIER, H. (1941) La jeunesse d'Auguste Comte et la formation du positivisme, Paris, Vrin (1970).

HALBWACHS, M. La classe ouvrière et les niveaux de vie. Recherches sur la hiérarchie des besoins dans la sociétés industrielles contemporaines,. Paris \& New York: Gordon and Breach, 1970. 
. La pysichologie colletive du raisonnament, In: HALBWACHS, M. Classes sociales et morphologie. Paris: Minuit, 1972.

. Esquisse d'une psychologie des classes sociales. Paris, Marcel Rivière, 1955.

HEILBRON, J. The rise of Social Theory, trad. Anglaise. Oxford: Polity Press, 1990.

. Ce que Durkheim doit à Comte, In: BESNARD, P. ; BORLANDI, M. \& VOGT, P. (Eds.). Division du travail et lien social. Durkheim, une siècle après. Paris: Presses Universitaires, 1993.

2001.

. Economic Sociology in France. European Societies 3(1),

KLAMER, A. \& COLANDER, D. The making of an economist. Boulder: Westview, 1990.

LEBARON, F. La croyance économique. Les economistes entre science et politique. Paris: Seuil, 2000.

. Les fondementes symboliques de l'ordre économique. Habilitation: Université Paris VII, 2003a.

. Le Savant, le politique et la Mondialisation, Broissieux: Èditions du croquant, 2003b.

LUKES, S. Émile Durkheim. His life and Works a Historical and Critical Study. London: Peguin, 1973.

MARX, K. Théories sur la plus-value, trad française. Paris: Éditions sociales, 1974-8.

. Le capital. Critique de l'économie politique, trad française. Paris : Éditions sociales, 1974.

MAUNIER, R. Recherches sur le échanges rituels en Afrique du Nord. L'Année Sociologique, 1927.

. Mélanges de sociologie Nord-Africaine. Paris: Alcan, 1930.

MAUSS, M. Essai sur le don. Fromes et raison de l'echange dans les societés archaïques, In: MAUSS, M. Sociologie et Anthropologie. Paris: Presses Universitaires de France, 1950.

PETIT, A. De Comte à Durkheim : un heritage ambivalent, In: BORLANDI, M. \& MUCHIELLI, L (Eds.) La sociologie et sa 
méthode. Les "Règles de la mèthode " un siècle après. Paris: L'Harmattan, 1995.

POLANYI, K. La grande transformation. Aux origines politiques et économiques de notre temp. Paris: Gallimard, 1983.

SIMIAND, D. La mèthode positive en sciences économiques. Paris: Alcan, 1912. 1930.

. Cours d'économie politique. Paris: Domat-Montchrestien, . Le salaire, la monnaie et l'evolution sociale. Paris: Alcan, 1932. $\mathrm{D}, 1,1934$.

. La monnaie, réalité sociale. Annales Sociologiques, série . La psychologie sociale des crises de fluctuations de courte durée. Annales Sociologiques, série D 2, 1937.

STEINER, P. Sociologie de la connaissance économique. Essai sur les rationalisations de la connaissance économique 1750-1850. Paris: Presses Universitaires de France, 1998.

. La sociologie Économique. Paris: La découverte, 1999.

. Marx et la sociologie économique. Cahiers Internationaux de Sociologie, 108 (1), 2000.

. The Sociology of Economic Knowledge. European Journal of Social Theory, 4 (4), 2001.

. Lécole durkheimienne et l'économie. Sociologie, religion et connaissance. Genève, Droz, 2005.

. La science de l'économie politque et les sciences sociales en France (1750-1840). Revue d'Histoire des Sciences Sociales, 15, 2006.

. Shumpeter's Sociology of Economic Knowledge: A Critical Assessment, à paraître, 2008.

SWEDBERG, R. Shumpeter. A Biography. Princeton: Princeton University, 1991.

WEBER, M. Cofucionisme et Taoïsm. Paris: Gallimard, 2000. 


\section{Apêndice 1: as ligações entre Comte, Durkheim e Bourdieu}

Durkheim conhecia a obra de Comte? A resposta é positiva sem sombra de dúvida. Diversos estudos mostraram a dívida de Durkheim com relação a Comte (LUKES, 1973; HEILBRON, 1993; PETIT, 1995) tanto quanto a ambivalência desta dívida na medida em que Durkheim reivindica pouco o pensamento de Comte, mesmo que esta relação se torne mais explícita a partir de 1900 (STEINER, 2005, cap.1). Em razão da similaridade intelectual que nós destacamos dentro da crítica metodológica, é possível pensar que Durkheim não apenas leu Comte, como leu de maneira bastante atenta. Claro, Durkheim pode ter sido influenciado por outros autores, a exemplo dos economistas alemães da escola histórica, entre os quais alguns (Karl Knies em especial) reconheciam na segunda edição de sua obra (Politische Ökonomie vom Standpunkte der geschichtlichen Methode, 1883) a proximidade de suas teses com aquela de Comte.

Os principais durkheimianos que se ocupam da economia (Halbwachs, Mauss e Durkheim) são mestres em filosofia (e dois dentre eles passaram pela École Normale Supérieure) o que permite pensar que eles também tiveram contato direto com a filosofia e a sociologia de Comte. O modo pelo qual Simiand (1934) apresenta a história das concepções da moeda é típica do marco comtiano distinguindo as fases teológica, metafísica e positiva do conhecimento.

Teria Bourdieu conhecido as obras de Comte, Durkheim e durkheimianos? Bourdieu não cita a obra de Comte, porém, o nome deste último volta frequientemente na "Profissão de Sociólogo". No que concerne a Durkheim e os durkheimianos, por outro lado, não há nenhuma dúvida, malgrado a estratégia de ocultação de suas fontes intelectuais que se pode atribuir a Bourdieu. Por exemplo, no capítulo sobre os cursinhos Durkheim é uma das duas referências implícitas - entretanto os sinais que indicam a 'A evolução pedagógica na França' são de tal evidencia que não podem escapar a qualquer um que tenha lido esta obra de Durkheim - ao lado do estudo de Weber sobre os mandarins chineses. Apesar disto, Durkheim faz parte dos autores regularmente citados por Bourdieu. No que diz respeito aos durkheimianos, a estratégia de ocultamento é mais 
eficaz. Por exemplo, na sua de sua obra sobre o trabalho na Algéria, Bourdieu se inspira na hipótese precisa de Halbwachs (1912) segundo a qual a discordância entre a socialização (dada por um nível de renda segundo a unidade de consumo dentro do lar a uma época anterior) e a estrutura da despesa pode ser explicada pela mobilidade social das famílias. Em síntese, o estudo de Halbwachs sobre as anomalias dentro dos estudos do orçamento enfatiza precisamente a situação descrita por Bourdieu (\& SAYAD, 1964; 1977a) em termos de habitus desajustado; entretanto Bourdieu não faz jamais referência a este autor, mesmo que ele tenha sabido valorizar a pessoa de Halbwachs em outra situação ( 0 assassinato de Maurice Halbwachs, 1987). Simiand é pouco citado, porém, Bourdieu o cita do começo ao fim de sua obra pelo trabalho do primeiro sobre a moeda. Bourdieu teria lido outras partes da obra de Simiand? Ainda, mesmo que seja difícil responder precisamente, as aproximações intensas entre as posições de Bourdieu e aquelas de Simiand sobre a escolástica econômica permitem pensar que seja este o caso (STEINER, 2005); aliás esta filiação intelectual foi reconhecida por Lebaron (2003). Bourdieu, com certeza, leu o Ensaio sobre a Dádiva, obra de Mauss, a qual ele interpreta de uma maneira muito específica. Porém, o trabalho de René Maunier é ao mesmo tempo utilizado por Bourdieu e sistematicamente marginalizado apesar de que este sociólogo durkheimiano atípico introduziu as noções de tempo e de estratégia nas trocas simbólicas (a twassa) que acontecem na Kabylia, precisamente na região à qual Bourdieu consagrou numerosos trabalhos etnológicos.

\section{Apêndice 2: uma tradição francesa rica de referências estrangeiras}

À exceção de Adam Smith, Comte parece ter conhecido apenas a economia política francesa; ele a conheceu muito superficialmente e sob a forma de generalidades, mesmo que estas tenham sido pertinentes (como a relação entre maquinismo e bem-estar da classe operária). Sua correspondência com John Stuart Mill mostra que Comte não espera nada mais desta ciência. Sua 'higiene cerebral' - parar de ler seus contemporâneos - o situa deste ponto de 
vista numa posição extrema, da qual se conhece, em matéria de econômica política apenas uma exceção notável com o julgamento positivo omitido sobre a obra de Charles Dunoyer, obra de um 'economicismo' radical - porque ele visava o trabalho que a sociedade deveria fazer sobre ela mesma por meio da educação entendida como produtora do capital moral necessário ao desenvolvimento da sociedade industrial.

Durkheim se apóia frequentemente sobre a economia política alemã e, no momento da redação de sua tese (DURKHEIM, 1970; 1975, vol.1) ele participa dos debates econômicos (por exemplo, a propósito da obra de Albert Shäffle). Na qualidade de professor de Ciência Social na Sorbonne, ele foi convidado durante uma sessão na Sociedade de Economia Política em 1908, para participar da discussão de um texto, pouco interessante, de M. Limousin sobre sociologia e economia; as observações de Durkheim fizeram com que este debate ocorresse entre ele e os economistas presentes, o orador sendo deixado de fora. Os economistas liberais apreciam moderadamente a obra de Durkheim (preferem antes $A$ divisão do trabalho social do que As regras do método) enquanto Charles Gide lhe faz uma acolhida bastante favorável na Revista de Economia Política resenhando cada volume do Année Sociologique bem como os trabalhos dos durkheimianos (Halbwachs e Simiand). Considerandose a sociologia econômica de Simiand e a crítica da economia política que ele desenvolve no Année, tem-se o exemplo de uma crítica sociológica muito bem informada. Este é inclusive o caso onde a informação é a mais continua, a mais sólida entre os casos considerados neste artigo. Entretanto, o aporte de Marx é deixado de lado, mesmo quando ele tivesse podido fazer eco diretamente aos trabalhos dos durkheimianos, especialmente quando está em questão a relação entre moeda e religião.

A obra de Bourdieu mais orientada na direção da economia (Bourdieu, 2000) mostra um conhecimento bastante distanciado da teoria econômica e emerge a impressão de leituras ad hoc mais do que de um trabalho sistemático. Tal trabalho de informação tem, entretanto, lugar no seio do grupo formado em torno dele com um fluxo contínuo de artigos consagrados à sociologia da economia nos Actes de La Recherche en Sciences Sociales e com os trabalhos de 
sociologia econômica oriundos do Centro de Sociologia Européia (LEBARON, 2000; 2003; DUVAL, 2004). A obra de Bourdieu suscitou numerosas reações da parte de economistas ou de sociólogos interessados pela economia (BOYER, 2003, 2004; BROCHIER, 1984; CAILLÉ, 1991, 1988; FAVEREAU, 2003). Somente a Escola da Regulação tentou fazer a ligação entre esta sociologia e a abordagem institucionalista da economia, ligação da qual, apesar do trabalho de Frédéric Lordon, nada saiu até o momento presente.

\begin{abstract}

\section{The French sociological tradition versus Political Economy}

This paper argues that there is a tradition - starting from Comte, moving through Durkheim and the Durkheimians and including the contemporary Bourdieu- which is of a intellectual nature. The text begins with a presentation of the three main forms of sociological critique of Political Economy that have unfolded since the end of the 19th century. It then goes on to show that the position developed by these three leading French sociologists cannot be explained solely on the basis of common background or of their (distant) relationship from Political Economy. Rather, it emphasizes the intellectual affinities running from Comte to Bourdieu and their common interest in delegitimizing Political Economy as a science, given the role attributed to social representations, whether the latter arise from economic activity itself or from social construction through educational institutions.
\end{abstract}

Keywords: Economic Sociology, critique of Political Economy, social representations. 
